
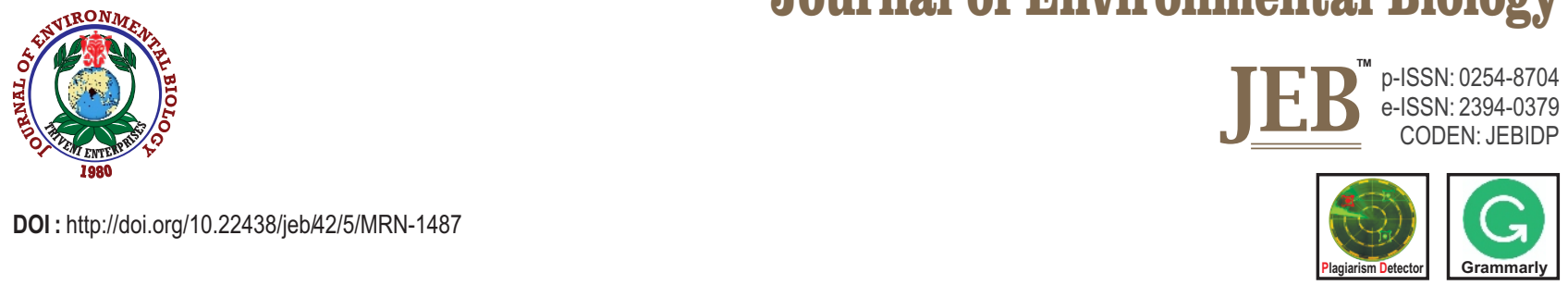

\title{
Collection and evaluation of genetic diversity in Dinanath grass (Pennisetum pedicellatum Trin.) for forage yield and leaf blight resistance
}

\author{
T. Singh ${ }^{1 *}$, S.N. Dheeravathu ${ }^{2}$, N. Dikshit ${ }^{3}$, N. Manjunatha ${ }^{4}$ and G. Sahay ${ }^{5}$ \\ ${ }^{1}$ Genetics and Plant Breeding, Crop Improvement Division, ICAR-Indian Grassland and Fodder Research Institute, Jhansi-284 003, India \\ ${ }^{2}$ Plant Physiology, Seed Technology Division, ICAR-Indian Grassland and Fodder Research Institute, Jhansi-284 003, India \\ ${ }^{3}$ Plant Genetic Resources, Crop Improvement Division, ICAR-Indian Grassland and Fodder Research Institute, Jhansi-284 003, India \\ ${ }^{4}$ Plant Pathology, Seed Technology Division, ICAR-Indian Grassland and Fodder Research Institute, Jhansi-284003, India \\ ${ }^{5}$ Genetics and Cytogenetics, Crop Improvement Division, ICAR-Indian Grassland and Fodder Research Institute, Jhansi-284 003, India \\ *Corresponding Author Email : tejveersinghbhu@gmail.com
}

\begin{abstract}
Aim: Dinanath grass is a drought tolerant multipurpose species with high potential for quality fodder in tropical regions. In India, it is distributed in eastern and southern parts. The gap in collection and exploitation of genetic diversity exists in Dinanath grass. Therefore, genetic diversity of Dinanath grass was collected and evaluated for utilization in genetic improvement of Pennisetum species for future fodder security.
\end{abstract}

Methodology: A total 28 accessions of Dinanath grass were collected from western and southern regions of Karnataka. Collected accessions were grown under rainfed conditions and evaluated for six qualitative and ten quantitative traits and response to leaf blight reaction. The evaluated accessions were analyzed by using different univariate and multivariate statistical tools.

Results: Dinanath accessions were categorized as per qualitative traits. Quantitative traits exhibited low $(7.43 \%)$ to high $(62.88 \%)$ coefficient of variation. Dry matter yield showed positive association with plant height, leaf area and tillers per plant. Cluster analysis classified Dinanath accessions into four distinct groups. The first five principal components explained $>85 \%$ of the total variation. Three accessions viz., IG-15-26, IG-15-30, IG-15-4 were identified as resistant against leaf blight disease; and donor accessions for agronomic traits were selected.

Interpretation: The indigenous Dinanath grass collection from Western Karnataka has ample diversity with reference to qualitative and biomass contributing traits; and resistance against leaf bight disease. The information generated on collected germplasm will assist the researchers in designing the Pennisetum genetic improvement programme.

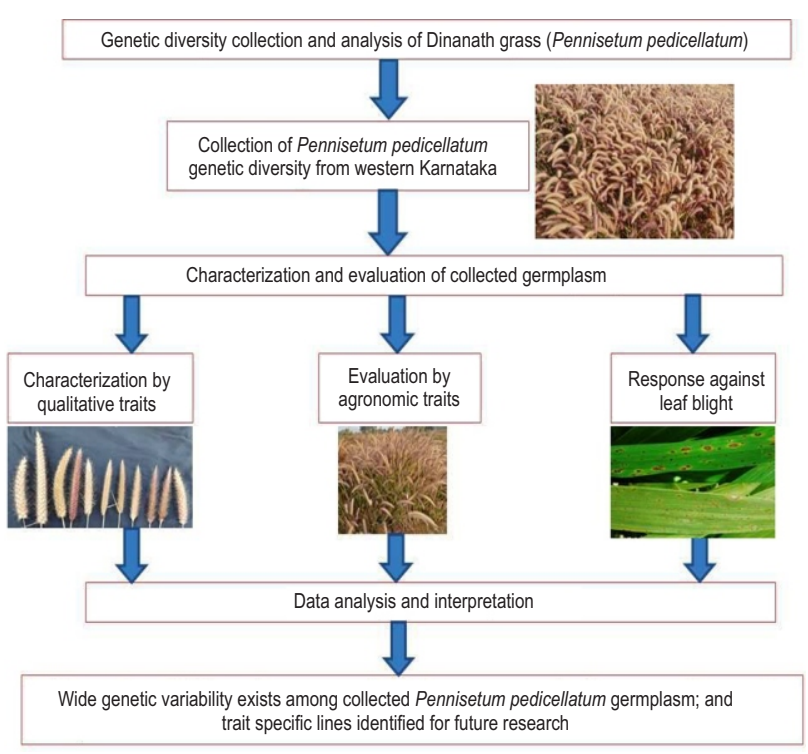

Key words: Bipolaris, Genetic diversity, Leaf blight, Multivariate analysis, Trait specific accessions

How to cite : Singh, T., S.N. Dheeravathu, N. Dikshit, N. Manjunatha and G. Sahay: Collection and evaluation of genetic diversity in Dinanath grass (Pennisetum pedicellatum Trin.) for forage yield and leaf blight resistance. J. Environ. Biol., 42, 1355-1362 (2021). 


\section{Introduction}

Dinanath grass (Pennisetum pedicellatum Trin.) belongs to the tribe Paniceae of family Poaceae and widely distributed in West Africa and India. In India, it is distributed in Andhra Pradesh, Bihar, Chhattisgarh, Jharkhand, Karnataka, Maharashtra, Odisha, West Bengal, Andaman \& Nicobar islands (Nayar et al., 2009; Upadhyaya et al., 2014). It is probably spread from India to the South East Asia and Northern Australia (Schmelzer, 1997). Dinanath grass is an annual, quick growing, luscious, leafy, thin stemmed and grows well even on poor, eroded soils (Mukherjee et al., 1982); and has very strong tolerance under severe drought conditions (Noitsakis et al., 1994). Dinanath grass is having high importance in providing high quantum of quality forage for maintaining animal nutritional security under drought and marginal soil besides its uses in ornamental, soil erosion control, improvement in the physical and chemical properties of the soil (Kumar and Jena, 1996) and as a bio-energy crop (Kumar and Ghosh, 2018). Dinanath grass is widely used for animal feed as green fodder, hay and silage. However, its biomass productivity and forage quality largely depends upon stage of harvest (Asmare et al., 2017; Tilahun et al., 2017). Crop cutting at 60-65 days results in a high crude protein (9.06\%), high crude fat $(2.55 \%)$ and low crude fibre $(28.95 \%)$ contents (Khan et al., 1995). Dinanath grass is also rich in sodium, potassium, phosphorus and calcium has the potential to be used in alleviating macro and micro-nutrients deficiencies in animals (Mustapha et al., 2018; Suleiman et al., 2020).

Genetic diversity is the base for survival of species and crop improvement programmes. Genetic diversity in different crops were collected and evaluated for conservation and utilization in breeding programme (Singh et al., 2014; Trivedi et al., 2018). For utilization in breeding programme, diversity of forage grasses were also analyzed by using different molecular, agronomic and quality traits (Saxena and Chandra, 2011; Zeki et al., 2009). P. pedicellatum though having multiple uses and is a wild relative of many cultivated species being contributing in form of donor for biotic and abiotic stress tolerance (Singh and Navi, 2000). But it has not received due attention from germplasm collectors. The diversity of $P$. pedicellatum distributed in different parts of the country is not represented in the collected genepool in International and national genebanks; and a geographical collection gaps are present mainly in southwestern part of India (Upadhyaya et al., 2014).

The continuous genetic erosion is a serious threat to the genetic variability accumulated over centuries, mainly by modern cultivation practices, concomitant natural catastrophes (droughts, floods, fire hazards etc.), human settlements, overgrazing etc. Climate change is likely to be an additional threat to agricultural biodiversity, increasing genetic erosion of landraces and threatening wild species, including crop wild relatives (Jarvis et al., 2008). Further, characterization and evaluation is the key to assess the potential and actual value of collected germplasm. Therefore, in order to prevent genetic erosion, Dinanath grass diversity was collected in wild habitats from unexplored areas of Karnataka and evaluated for the utilization in future Pennisetum improvement programme through sustainable ways.

\section{Materials and Methods}

Collection of genetic diversity: Four districts of western and southern Karnataka, India viz., Belgaum, Dharwad, Uttara Kannada and Bengaluru urban were explored. Passport characters e.g. village, block, district, latitude, longitude, altitude and habitat were recorded at the collection sites. The samples were mainly collected in the form of inflorescence, seeds and rooted slips. Random sampling method was followed for collecting single panicle from at least 50 plants, with 95 percent certainty, all the alleles at a random locus occurring in the target population with frequency greater than 0.05 (Marshall and Brown, 1975).

\section{Evaluation of collected germplasm}

Location of experiment: The experiment was conducted during 2018-2019 at the Central Research Farm of the ICAR-Indian Grassland and Fodder Research Institute, Jhansi, India (latitude $25^{\circ} 31^{\prime} \mathrm{N}$, longitude $78^{\circ} 32^{\prime} \mathrm{E}$ and altitude $237 \mathrm{~m}$ above $\mathrm{msl}$ ). The experimental site is characterized by a semi-arid climate with extreme temperatures during summer $\left(43-46^{\circ} \mathrm{C}\right)$ and winter (as low as $2^{\circ} \mathrm{C}$ ). The soil was deep, moderately well drained, and brown to dark grayish brown with fine loamy texture. Seeds of collected germplasm (28 accessions) and one check (cv. Bundel Dinanath-2) were grown in pots and after reaching seedling height around $30 \mathrm{~cm}$ they were then transplanted in the field. Each accession was planted in a plot size of $3 \mathrm{~m} \times 1 \mathrm{~m}$ in CRB design with two replications. Line to line and plant to plant distance was maintained at $50 \times 50 \mathrm{~cm}$ with $1 \mathrm{~m}$ spacing between two plots. The crop was grown under rainfed conditions and managed following the standard agricultural practices.

Data recording and statistical analysis: Meteorological observations viz., weekly mean temperature $\left({ }^{\circ} \mathrm{C}\right)$, rainfall $(\mathrm{mm})$, relative humidity $(\%)$ and evaporation $(\mathrm{mm})$ were recorded during the crop growth period. Data was recorded on six qualitative traits including early plant vigour, plant growth habit, culm colour, branching pattern, leaf hairiness, spikelet colour; and ten quantitative traits i.e., plant height $(\mathrm{cm})$, days to maturity, flag leaf length $(\mathrm{cm})$, flag leaf width $(\mathrm{cm})$, penultimate ${ }^{-1}$ leaf length $(\mathrm{cm})$, penultimate ${ }^{-1}$ leaf width $(\mathrm{cm})$, peduncle length $(\mathrm{cm})$, panicle length $(\mathrm{cm})$, number of tillers per plant, dry matter yield per plant $(\mathrm{g})$. Data on qualitative traits were recorded on plot basis and on quantitative traits were recorded on five representative plants.

The accessions were classified based on the descriptor states of qualitative traits and presented through bar graph. The mean data of quantitative traits were analyzed by univariate statistics e.g. means, ranges and variance; and multivariate analysis including cluster, correlation and principal component. The correlations among the traits were based on the Pearson 
Correlation Coefficients. Clustering of accessions was carried out using 'Cluster' package of SAS statistical software with squared euclidean distance. Dendrogram was constructed on the basis of fusion level to examine similarities in the pattern of performance among accessions. Data of all characters were standardized to a mean of zero and variance of one and Principal Component Analysis (PCA) was done to investigate the importance of different traits in explaining multivariate polymorphism in Dinanath grass accessions.

Leaf blight (Bipolaris sorokiniana) severity was recorded under natural epiphytotic conditions. The accessions which showed resistant and moderately resistant under natural conditions were further screened in-vitro for confirmation. The screening was carried out in petri dishes by inoculating detached leaves with blight spores using the spot inoculation method. Disease severity was recorded through visual estimation using disease scale (0-4) given by Takahashi et al. (2009) and based on disease reaction the accessions were classified as highly resistant (HR), resistant (R), moderately resistant (MR), susceptible (S) and highly susceptible (HS).

\section{Results and Discussion}

Twenty eight accessions of Dinanath grass were collected from diverse ecological niches of four western and southern Karnataka districts viz., Belgaum, Dharwad, Uttar Kannada and Bangaluru urban. During evaluation of collected germplasm the meteorological observations including weekly temperature, rainfall, relative humidity and evaporation were recorded. The average minimum temperature varied from 4.8$22.9^{\circ} \mathrm{C}$, maximum temperature $21.9-35.8^{\circ} \mathrm{C}$, relative humidity (RH I) 75-94\%, RH II 36-85 and evaporation 2.3-5.4 mm. The total precipitation during crop season was $191.8 \mathrm{~mm}$ and most of the precipitation $(175.6 \mathrm{~mm})$ occurs during the first week of transplanting of crop and remaining $(16.2 \mathrm{~mm})$ occur in third week and after that no rainfall occur and the crop survived on residual soil moisture. Being a $\mathrm{C} 4$ plant Dinanath grass is more efficient in utilization of water and nitrogen. The present study also support that Dinanath grass is drought resistant and can grow under prevailing minimal rainfall condition as reported earlier by Noitsakis et al. (1994).

Analysis of morphological diversity revealed that mostly accessions showed good early plant vigour, purple type culm, medium branching pattern, leaf hairiness and purple type spikelets. Distribution of Dinanath accessions as per descriptor states are mentioned in Fig. 1. Out of the total, one accession DSN/MK-92 with purple culm and spikelet colour can be grown as morphological marker and also for ornamental value. Quantitative traits exhibit low $(7.43 \%)$ to high $(51.99 \%)$ value of coefficient of variation (CV). Plant height and dry matter yield per plant are important traits on fodder point of view. Dry matter yield per plant varied from $11.4 \mathrm{~g}$ to $264.4 \mathrm{~g}$ with $51.99 \% \mathrm{CV}$ and height of the plant varied from $47.70 \mathrm{~cm}$ to $106.6 \mathrm{~cm}$ with a mean of $79.88 \mathrm{~cm}$ and high CV (21.44\%) suggests significant variability among the accessions. Days to maturity varies from 98 days to 127 days and showed low CV, indicates less variability among evaluated

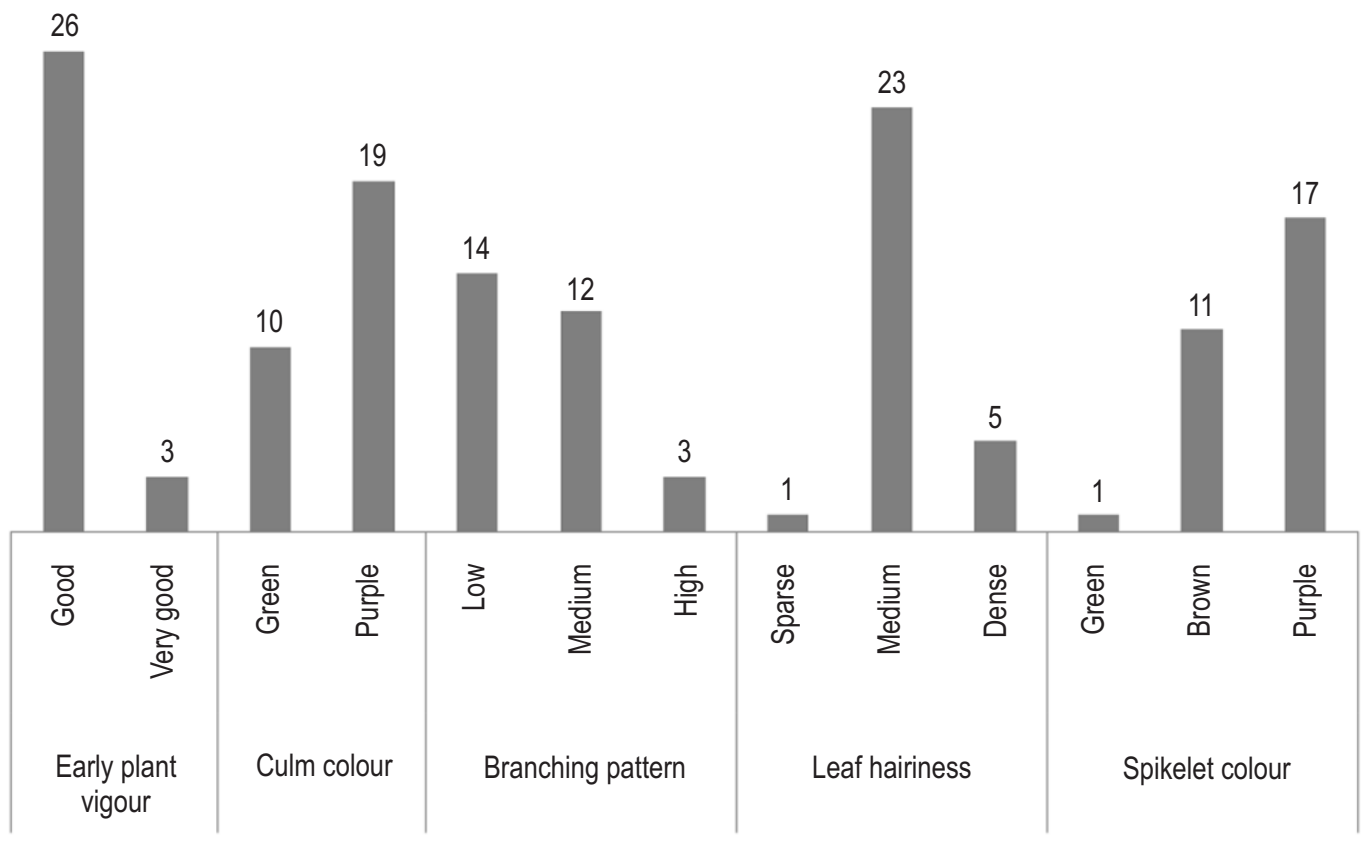

Fig. 1: Distribution of Pennisetum pedicellatum accessions as per expression of descriptor states of qualitative traits. 


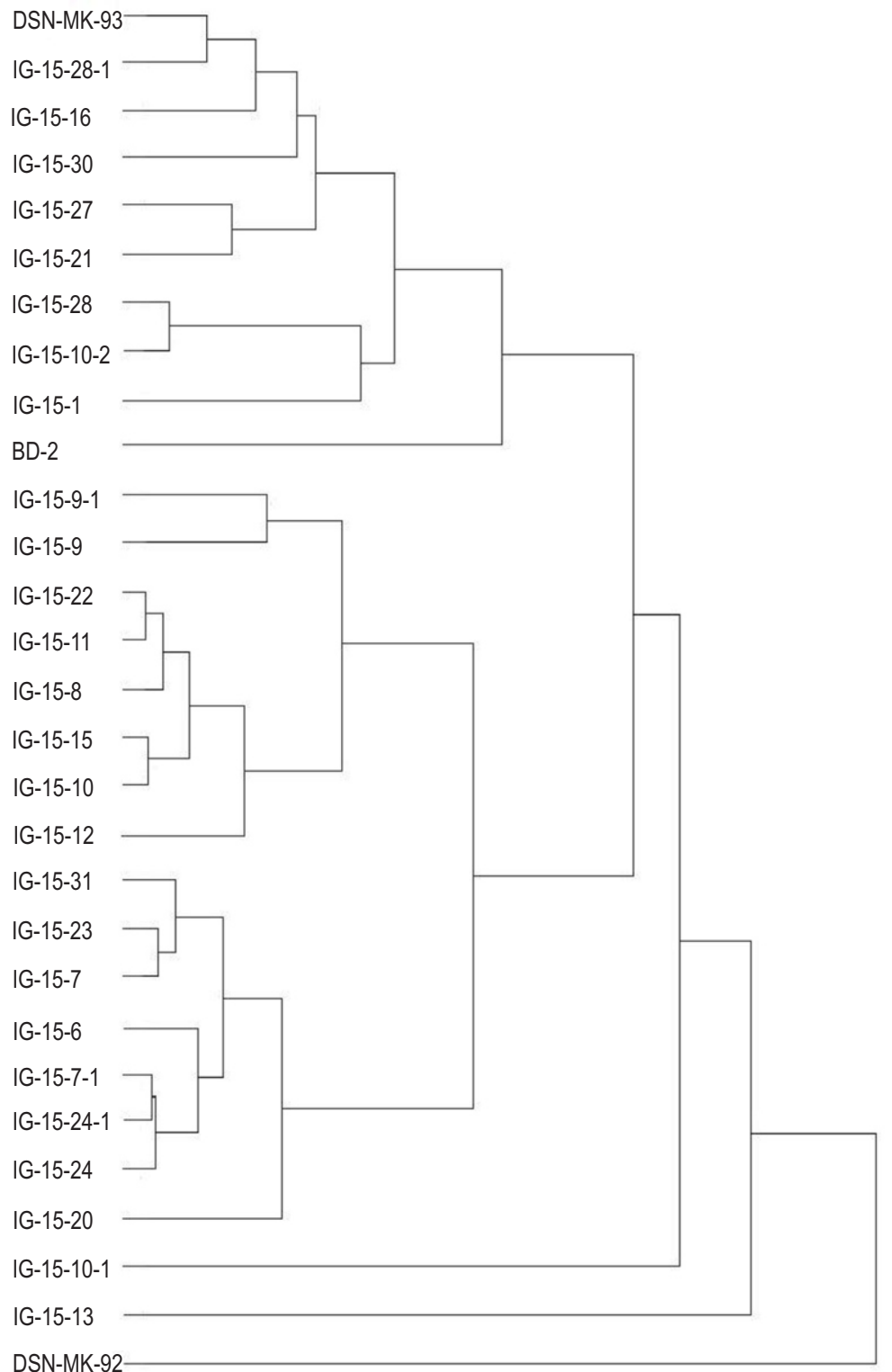

Fig. 2: Distribution of Dinanath grass accessions into different clusters based on 10 agronomic traits.

accessions. Moderate variability was recorded for flag leaf length, penultimate $^{-1}$ leaf length, peduncle length and panicle length whereas high CV were recorded for flag leaf width, penultimate ${ }^{-1}$ leaf width, number of tillers per plant, plant height and dry matter yield per plant (Table 1). High variability in biomass yield and its contributing traits were also reported in global Dinanath grass collection by Upadhyaya et al. (2014) and Mishra et al. (2009). High variability recorded among biomass contributing traits suggest further scope of improvement through new breeding tools. However, further exploration should be planned to incorporate more variability in days to maturity and qualitative traits where low variability was observed in the present study.
Correlation coefficients analysis indicates mutual relationship between various metric traits and determines the component characters which are associated with biomass yield. Out of total 45 associations among 10 agronomic traits, 7 associations were significant $(p<.05)$ either in positive or negative direction (Table 2). Panicle length was strongly correlated with peduncle length $(r=0.78)$ followed by penultimate ${ }^{-1}$ leaf length with panicle length ( $r=0.66)$ and peduncle length $(r=0.60)$; and flag leaf length with flag leaf width (0.50). Tillers per plant and penultimate ${ }^{-1}$ leaf length showed negative correlation ( $r=-0.71)$ followed by panicle length with tillers per plant $(r=-0.47)$. Dry matter yield per plant (DMY) showed positive association with all studied traits; 
Table 1: Variation in agronomic traits among 29 Dinanath grass accessions evaluated in Central India

\begin{tabular}{lllllll}
\hline Traits & Mean \pm SE & Variance & Kurtosis & Skewness & Range & CV\% \\
\hline Plant height $(\mathrm{cm})$ & $79.88 \pm 3.18$ & 293.55 & -0.844 & -0.24 & $47.70-106.6$ & 21.44 \\
Days to maturity & $115.55 \pm 1.59$ & 73.68 & -1.04 & -0.38 & $98-127$ & 7.43 \\
Flag leaf length $(\mathrm{cm})$ & $6.85 \pm 0.24$ & 1.72 & -0.59 & 0.23 & $4.50-9.44$ & 19.16 \\
Flag leaf width $(\mathrm{cm})$ & $0.30 \pm 0.02$ & 0.01 & 0.94 & 1.18 & $0.16-0.64$ & 39.87 \\
Penultimate- 1 leaf length $(\mathrm{cm})$ & $11.52 \pm 0.30$ & 2.61 & 3.98 & -1.5 & $5.90-13.92$ & 14.02 \\
Penultimate $^{-1}$ leaf width $(\mathrm{cm})$ & $0.63 \pm 0.03$ & 0.03 & -0.24 & -0.09 & $0.24-0.98$ & 27.57 \\
Peduncle length (cm) & $29.64 \pm 0.82$ & 19.56 & 1.27 & -0.84 & $17.50-37.50$ & 14.92 \\
Panicle length $(\mathrm{cm})$ & $13.89 \pm 0.41$ & 4.8 & 1.17 & -0.08 & $8.14-19.18$ & 15.78 \\
Tillers per plant & $49.3 \pm 4.32$ & 542.29 & 7.33 & 2.33 & $19.50-139.40$ & 47.20 \\
Dry matter yield per plant $(\mathrm{g})$ & $136 \pm 13.21$ & 5065.83 & -0.84 & 0.00 & $11.4-264.4$ & 51.99 \\
\hline
\end{tabular}

Table 2: Correlation coefficient among quantitative traits recorded on 29 accessions of Dinanath grass

\begin{tabular}{|c|c|c|c|c|c|c|c|c|c|}
\hline Traits! & PHT & DTM & FLL & FLW & PLL & PLW & PDL & PNL & TPP \\
\hline DTM & 0.07 & & & & & & & & \\
\hline FLL & 0.31 & -0.05 & & & & & & & \\
\hline FLW & -0.01 & -0.12 & $0.50^{* *}$ & & & & & & \\
\hline PLL & 0.14 & 0.23 & 0.23 & -0.07 & & & & & \\
\hline PLW & -0.18 & 0.16 & 0.27 & 0.36 & 0.14 & & & & \\
\hline PDL & 0.03 & 0.27 & 0.18 & 0.05 & $0.60^{* *}$ & -0.01 & & & \\
\hline PNL & 0.18 & 0.20 & 0.03 & -0.13 & $0.66^{\star *}$ & -0.21 & $0.78^{* *}$ & & \\
\hline TPP & -0.15 & -0.16 & -0.25 & 0.20 & $-0.71^{* *}$ & -0.11 & -0.27 & $-0.47^{*}$ & \\
\hline DMY & $0.42^{*}$ & 0.18 & 0.16 & 0.02 & 0.23 & 0.19 & 0.15 & 0.22 & 0.29 \\
\hline
\end{tabular}

!PHT-Plant height, DTM-Days to maturity, FLL-Flag leaf length, FLW-Flag leaf width, PLL-Penultimate ${ }^{-1}$ leaf length, PLW-Penultimate ${ }^{-1}$ leaf width, PDL-Peduncle length, PNL-Panicle length, TPP-Tillers per plant, DMY-Dry matter yield per plant.

${ }^{*}=$ significant at $5 \%$ probability level and ${ }^{* *}=$ highly significant at $1 \%$ probability level

maximum value of association was recorded with plant height $(r=0.42)$, followed by tillers per plant, penultimate ${ }^{-1}$ leaf length, panicle length, peduncle length, penultimate $e^{-1}$ leaf width and days to maturity. The positive association of DMY with agronomic traits (plant height, tillers per plant and leaf length) may result from better competition for radiant energy with extended days to harvest. A similar correlation was also observed in other studies (Asmare et al., 2017; Gadisha et al., 2019). The principal component (PC) analysis was effective in that the first five PC accounted for $85.37 \%$ of the total variation among the 29 germplasm accessions of Dinanath grass (Table 3). Characters with high variability are expected to provide high level of gene transfer during breeding programs. Accordingly, in the first PC, penultimate ${ }^{-1}$ leaf length, panicle length and peduncle length were the most important traits contributing to variation that explained $29.69 \%$ of the total variance. In the second PC, which describe $18.97 \%$ of the total variance originated mainly from penultimate ${ }^{-1}$ leaf width, flag leaf length and flag leaf width. Similarly, DMY, flag leaf width, leaflet length constituted a large part of total variance explained by the third PC. In the fourth PC, which describe $11.59 \%$ of the total variance, originated mainly from penultimate ${ }^{-1}$ leaf width and peduncle length. The fifth PC describes $9.13 \%$ mainly due to days to maturity, tillers per plant and plant height.
The cluster analysis placed 29 Dinanath grass accessions into five clusters (Fig. 2). Cluster one includes 10 accessions, cluster two 16 accessions while cluster third, fourth and fifth with one accession each. Dinanath accessions falling in different clusters were most diverged than others viz., DSN MK-93, BD-2, IG-15-91, IG-15-20, DSN-MK-92 and check variety Bundel Dinanath-2. This indicated that these accessions are most suitable for utilization in future genetic improvement programme. Grouping of accessions showed that cluster I and cluster II pooled with maximum number of accessions which indicated similarities for phenotypic traits and genetic lineage. The reason for grouping of accessions of same geographic origin into different clusters might be due to the different genetic architecture resulted wide divergence in morphological features. The distribution of germplasm accessions in the study indicated that the geographical origin did not have any bearing on clustering pattern. Though, all genotypes were collected from Karnataka state but placed in different clusters, which indicated that the geographical distribution and genetic divergence did not follow the same trend. The genetic drift and selection could be the cause greater diversity within a geographical region. The results are in agreement with the previous findings of Upadhyaya et al. (2014) for similar reasons of diversity in Dinanath grass. 
Table 3: Eigen values and Eigen vectors of the important principal components $(P C)$ for variation among the 29 accessions of Dinanath grass

\begin{tabular}{|c|c|c|c|c|c|}
\hline Traits & PC1 & $\mathrm{PC} 2$ & PC3 & $\mathrm{PC} 4$ & PC5 \\
\hline Plant height & 0.154 & -0.003 & 0.191 & -0.753 & 0.343 \\
\hline Days to maturity & 0.212 & 0.126 & -0.425 & 0.091 & 0.715 \\
\hline Flag eaf length & 0.175 & 0.460 & 0.390 & -0.259 & -0.025 \\
\hline Flag leaf width & -0.045 & 0.444 & 0.482 & 0.190 & 0.165 \\
\hline Penultimate $^{-1}$ leaf length & 0.517 & 0.078 & -0.090 & 0.027 & -0.236 \\
\hline Penultimate ${ }^{-1}$ leaf width & 0.024 & 0.558 & -0.070 & 0.328 & -0.079 \\
\hline Peduncle length & 0.456 & -0.116 & 0.194 & 0.351 & 0.230 \\
\hline Panicle length & 0.493 & -0.266 & 0.117 & 0.119 & 0.056 \\
\hline Tillers per plant & -0.424 & -0.104 & 0.198 & 0.212 & 0.475 \\
\hline Dry matter yield per plant & 0.000 & -0.403 & 0.543 & 0.173 & -0.006 \\
\hline Eigen value & 2.97 & 1.90 & 1.60 & 1.16 & 0.91 \\
\hline Percent of variance explained & 29.69 & 18.97 & 15.99 & 11.59 & 9.13 \\
\hline Cumulative percent of total variance explained & 29.69 & 48.65 & 64.65 & 76.24 & 85.37 \\
\hline
\end{tabular}

Table 4: Selection of superior Dinanath grass accessions for agronomic traits

\begin{tabular}{|c|c|c|}
\hline Traits & Value & Genotype (trait value) \\
\hline Plantheight & $>100 \mathrm{~cm}$ & IG-15-12 (100.2), IG-15-1 (101.8), IG-15-15 (102.3), IG-15-10 (103.2), IG-15-27 (106.6) \\
\hline Days to maturity & $\leq 108$ days & DSN-MK-92 (98), Bundel Dinanath-2 (100), IG-15-1 (103), IG-15-28 (106), IG-15-22 (108) \\
\hline Days to maturity & $\geq 124$ days & IG-15-10-1 (124), IG-15-30 (125), IG-15-27 (126), IG-15-7-1 (127), IG-15-7 (127) \\
\hline Flag leaf & Length $(\geq 8.4 \mathrm{~cm})$ & IG-15-27 (8.4), IG-15-21 (8.8), IG-15-16 (8.8), IG-15-13 (9.0), IG-15-28 (9.4) \\
\hline & Width $(\geq 0.4 \mathrm{~cm})$ & IG-15-27 (0.4), IG-15-28 (0.5), IG-15-28-1 (0.5), IG-15-30 (0.6), IG-15-1 (0.6) \\
\hline Penultimate $^{-1}$ leaf & $\begin{array}{l}\text { Length }(\geq 13 \mathrm{~cm}) \\
\text { Width }(\geq 0.8 \mathrm{~cm})\end{array}$ &  \\
\hline Panicle length & Large $(\geq 15.8 \mathrm{~cm})$ & IG-15-11 (15.8), IG-15-9 (16.8), IG-15-22 (16.8), IG-15-8 (17.1), IG-15-9-1 (19.2) \\
\hline Tillers per plant & $\geq 69$ & IG-15-30 (69.0), IG-15-9 (72.6), IG-15-16 (74.0), IG-15-20 (90.3), DSN-MK-92 (139.4) \\
\hline $\begin{array}{l}\text { Dry biomass per plant } \\
\text { Spot blotch reaction }\end{array}$ & $\begin{array}{l}\geq 212.0 \mathrm{gms} \\
\text { Resistant } \\
\text { Susceptible }\end{array}$ & $\begin{array}{l}\text { IG-15-12 (264.4), IG-15-15 (254), IG-15-9 (244), DSN-MK-93 (218.8), IG-15-16 (212) } \\
\text { IG-15-26, IG-15-30, 1G-15-4 } \\
\text { IG-15-11, IG-15-3 }\end{array}$ \\
\hline
\end{tabular}

Since the use of resistant varieties is considered to be the best approach for disease management in forage crops, therefore, the collected accessions along with Bundel Dinanath-2 cultivar were screened against Bipolaris sorokiniana. Among 29 accessions screened, three were resistant (IG-15-26, IG-15-30 and 1G-15-4), four moderately resistant (IG-15-1, IG-15-3, IG-1511 and IG-15-27), seventeen susceptible and five highly susceptible in natural field conditions. Resistant and moderately resistant accessions were further verified in-vitro. The response of resistant accessions was similar to natural conditions but response of moderately resistant accessions differed under laboratory condition. Out of four moderately resistant accessions, two showed similar reaction and two (IG-15-3, IG-15-11) showed highly susceptible reaction. Our result is in accordance with Ojha et al. (2017) who showed that the disease response of wheat genotypes to leaf blotch pathogen varied between natural and artificial screening. Artificial screening verifies the results of natural screening (Chand et al., 2008), thus artificial screening of genotypes is very important to confirm field resistance for accuracy. B. sorokiniana affects wide variety of grasses and cereals, and resistant donor against this disease has been identified in wheat and barley (Kumar et al., 2019; Singh et al., 2014). The distinct resistance identified in these accessions can be used as valuable source in breeding for spot blight disease in Dinanath grass and related species. Donor accessions were identified for agronomic traits and reaction to leaf blight disease (Table 4). Genotypes viz., IG-15-10, IG-15-9 and IG-15-15 having good biomass yield, tall height, medium maturity and moderate tolerance to leaf blight disease needs to be tested for biomass production potential at multi-location for release as variety. High biomass producing accessions of Dinanath grass were also identified by Hidosa et al. (2020); Gadisha et al. (2019) and Yirgu et al. (2017). Donors for various traits in different crops were identified for enhance utilization of conserved germplasm in breeding programme (Kaur et al., 2018; Singh et al., 2014). Dinanath grass being a crop wild relative of Pearl millet and other cultivated Pennisetum species, the identified donor accessions could be utilized for transfer of useful novel genes like resistance against blight disease, tillering capacity and drought tolerance by exploiting new molecular breeding tools. Promising accessions 
identified for high dry matter yield and resistant to leaf blight disease will help in designing Dinanath grass improvement program and thus will also boost up fodder production and productivity in marginal land of low rainfall areas.

\section{Acknowledgments}

The authors are thankful to the Director, ICAR-IGFRI, Jhansi, Uttar Pradesh for facilities and encouragement during the course of investigation and In-charge RRS, IGFRI, Dharwad for facilities provided during the exploration and collection of forage species from Karnataka, India.

\section{Add-on Information}

Authors' contribution: T. Singh: Contributed to the design and implementation of the research, germplasm collection, data recording and analysis, drafted and final the manuscript; S.N. Dheeravathu: Involved in germplasm collection and data recording; N. Dikshit: Processed the experimental data, data recording, performed the analysis and contributed to the final manuscript; N. Manjunatha: Performed disease analysis; G. Sahay: Aided in interpreting the results.

Research content: The research content is original and has not been published elsewhere.

\section{Ethical approval: NotApplicable}

Conflict of interest: The authors declare that there is no conflict of interest.

\section{Data from other sources: NotApplicable}

Consent to publish: All authors agree to publish the paper in Journal of Environmental Biology.

\section{References}

Asmare, B., S. Demeke, T. Tolemariam, F. Tegegne, A. Haile and J. Wamatu: Effects of altitude and harvesting dates on morphological characteristics, yield and nutritive value of desho grass (Pennisetum pedicellatum Trin.) in Ethiopia. Agric. Nat. Resour., 51, 148-153 (2017).

Chand, R., D. Sen, K.D. Prasad, A.K. Singh, B.M. Bashyal, L.C. Prasad and A.K. Joshi: Screening for disease resistance in barley cultivars against Bipolaris sorokiniana using callus culture method. Indian J. Exp. Biol., 46, 249-253 (2008).

Gadisa, B., T. Dinkale and M. Debela: Evaluation of Desho Grass (Pennisetum pedicellatum Trin) lines for their adaptability at Mechara Research Station, Eastern Oromia, Ethiopia. J. Ecol. Nat. Environ., 11, 26-32 (2019).

Hidosa, D., B. Belachew and S. Kibiret: Evaluation of Desho (Pennisetum pedicellatum) grass varieties for dry matter yield and chemical composition in South Omo Zone, South Western Ethiopia. Agri. Res. Tech., 25, 001-008 (2020).

Jarvis, A., A. Lane and R. Hijmans: The effect of climate change on crop wild relatives. Agr. Ecosyst. Environ., 126, 13-23 (2008).
Kaur, V., S. Kumar, R. Yadav, D.P. Wankhede, J. Aravind, J. Radhamani, J.C. Rana and A. Kumar: Analysis of genetic diversity in Indian and exotic linseed germplasm and identification of trait specific superior accessions. J. Environ. Biol., 39, 702-709 (2018).

Khan, A.K.F., M. Paramathma, A. Amirthadevarathinam, N. Sivasamy, D. Sudhakar and M.S.C. Bose: Deenanath Co-1: A new annual fodder grass for Tamil Nadu. Madras Agric. J., 82, 510-511 (1995).

Kumar, S. and P. Ghosh: Sustainable bio-energy potential of perennial energy grass from reclaimed coalmine spoil (marginal sites) of India. Renew. Ener., 123, 475-485 (2018).

Kumar, U. and S.C. Jena: Trial of integrated biotechnical approach in biological reclamation of coal mine spoil dumps in South-Eastern Coalfields Limited (SECL), Bilaspur (Madhya Pradesh). Indian For., 122, 1085-1091 (1996).

Kumar, U., S. Kumar, R. Prasad, M.S. Röder, S. Kumar, R. Chand, V.K. Mishra and A.K. Joshi: Genetic gain on resistance to spot blotch of wheat by developing lines with near immunity. Crop Breed. Genet. Genom., 1, e190017 (2019).

Marshall, D.R. and A.H.D. Brown: Optimum sampling strategies in genetic conservation. In: Genetic Resources for Today and Tomorrow (Eds.: O.H. Frankel and J.G. Hawkes). Cambridge, pp. 53-80 (1975)

Mishra, U.S., A.K. Roy, U.P. Singh, O.P.S. Verma, N.K. Shah, P. Saxena, P. Kaushal, L.K. Karnani and D.R. Malaviya: Deenanath grass (Pennisetum pedicellatum Trin.) germplasm catalogue. IGFRI Jhansi, India, pp.35 pages (2009).

Mukherjee, A.K., M.A. Roquib, S.K. Bandopadhyay and B.B. Mandal: Review of research on Deenanath grass (Pennisetum pedicellatum Trin.). Forage Res., 8, 11-17 (1982).

Mustapha, S., A.M. Safiya, Y. Nasiru, M. Alhassan, Y.M. Sahabi, N. Bello and A.Y. Khadijah: Nutritional composition of Pennisetum pedicellatum Trin Grass. Int. J. Sci. Environ. Technol., 6, 56-59 (2018).

Nayar, M.P., A.K. Singh and K.N. Nair: Agrobiodiversity hotspots in India: Conservation and Benefit Sharing, Vol. II, 309 pages (2009).

Noitsakis, B., A. Nastis, Z. Koukoura, N.P. Zervas and J. Hatziminaoglou: The optimal exploitation of marginal Mediterranean areas by extensive ruminant production systems. EAAP Publication No. 83. Proceedings of an International Symposium organized by HSAP, EAAP and CIHEAM, Thessaloniki, Greece, pp. 217-220 (1994).

Ojha, A., G. Singh, B.S. Tyagi, V. Singh, Rajita and P. Kumar: Screening of resistance source against spot blotch disease caused by Bipolaris sorokiniana in Triticum aestivum L. Int. J. Adv. Res., 5, 2328 (2017).

Saxena, R. and A. Chandra: Transferability of STS markers in studying genetic relationships of marvel grass (Dichanthium annulatum). $J$. Environ. Biol., 32, 701-706 (2011).

Schmelzer, G.H.: Review of Pennisetum section Brevivalvula (Poaceae). Euphytica, 97, 1-20 (1997).

Singh, S.D. and S.S. Navi: Genetic resistance to pearl millet downy mildew II. Resistance in wild relatives. J. Mycol. Plant Pathol., 30, 167-171 (2000).

Singh, T., V.K. Mishra, L.C. Prasad and R. Chand: Variation for infection response to Bipolaris sorokiniana and identification of trait specific sources in barley (Hordeum vulgare L.) germplasm. Aust. J. Crop Sci., 8, 909-915 (2014).

Suleiman, M., A.Y. Khadija, Y. Nasiru, M.A. Safiya, M. Alhassan and H.J. Bello: Mineral and anti-nutrient composition of Pennisetum pedicellatum Trin. Grass. Res. J. Food Sci. Nut., 5, 78-84 (2020).

Takahashi, W., Y. Miura and T. Sasaki: A novel inoculation method for evaluation of grey leaf spot resistance in Italian ryegrass. J. Plant 
Pathol., 91, 171-176 (2009).

Tilahun, G., B. Asmare and Y. Mekuriaw: Effects of harvesting age and spacing on plant characteristics, chemical composition and yield of Desho Grass (Pennisetum pedicellatum Trin.) in the highlands of Ethiopia. Trop. Grassl., 5, 77-84 (2017).

Trivedi, A.K., S.K. Verma and R.K. Tyagi: Pheno-physiological evaluation of finger millet germplasm of Central Himalayan Region. $\mathrm{J}$. Environ. Biol., 39, 31-36 (2018).

Upadhyaya, H.D., K.N. Reddy, S. Singh, M.I. Ahmed, V. Kumar and S. Ramachandran: Geographical gaps and diversity in
Deenanath grass (Pennisetum pedicellatum Trin.) germplasm conserved at the ICRISAT genebank. Indian J. Plant Genet. Resour., 27, 93-101 (2014).

Yirgu, T., S. Mengistu, E. Shanku and F. ljara: Desho grass (Pennisetum pedicellatum) lines evaluation for herbage yield and quality under irrigation at Wondogenet. Am. Eurasian J. Agric. Environ. Sci., 17, 427-431 (2017).

Zeki, A., I. Ayan, O. Asci, U. Basaran and H. Mut: Biodiversity in morphological properties and nutritional values of forage grass species. J. Environ. Biol., 30, 583-589 (2009). 